مجلة الجديد في البحوث الزر اعية (كلية الزراعة ـ سابا باثنا) $r \cdot 0$ 


\title{
Summary \\ The Competitiveness of Egyptian Potato Exports to The Most Important Markets of The European Union
}

\author{
Hossam El Din Mohamed Seddik \\ Associate Professor of Agricultural Economics \\ Higher Institute of Agricultural Co-operation
}

\begin{abstract}
The study examines the competitiveness of Egyptian potato exports to the most important markets of the European Union by calculating the competitiveness indices during the period (2008-2017). The trend of Egyptian agricultural exports to the European Union markets showed an increasing growth rate of about $1.3 \%$, the trend of quantity and value of Egyptian potato exports increased at a rate of $9.2 \%$ and $8.4 \%$ respectively, while the trend of the export price of Egyptian potato is about 2.5\% during the average period (20082017). There was also a positive correlation between the quantity of Egyptian potato exports to the most important European markets and the total domestic production of potatoes. There is an inverse relationship between the quantity of potato exports and the total domestic consumption of potatoes, price of exporting potatoes where the $1 \%$ change in the amount of local consumption of potatoes leads to a change in the opposite direction of potato exports to Greece, Germany and Netherlands by about $5.34 \%, 21.8 \%$ and $7.3 \%$, respectively. The results of the standard estimation of the potato export target for the major European markets, using Nerlove's partial adjustment model, showed that the most important determinants of potato exports are the local potato production, the export price of Egyptian potatoes, it was found that a change of $1 \%$ in the amount of local production of potatoes leads to a change in the same direction of potato exports to the Italy, Greece by about $1.1 \%, 0.4 \%$, respectively. Change of $1 \%$ in the export price of Egyptian potatoes, which leads to a change in the opposite direction, of potato exports to the Germany, United Kingdom by about $4.2 \%, 0.67 \%$ respectively. The results of the forecasting of the amount of potato exports, for the most important European markets, until 2023 indicate that the quantity of potato exports is expected to decline by $7.9 \%, 7.7 \%, 47.9 \%$ and $32.4 \%$ for Italy, Greece, U.K and Netherlands respectively from 2017.
\end{abstract}

Key words: Indicators of competitiveness, Egyptian potato exports, European Union markets. 
وقد أمكن التتبؤ بكمية صادرات البطاطس المصري لأهم الأسواق الأوروبية حتى عام rr ب باستخدام منهجية

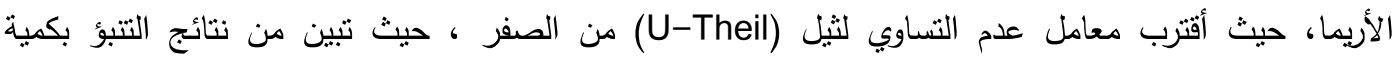

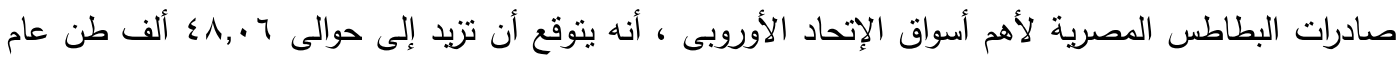

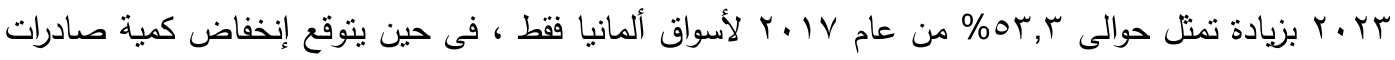

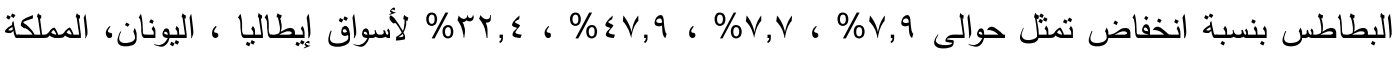

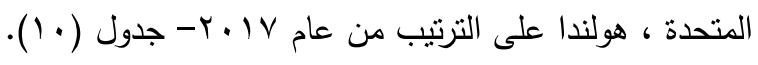

جدول ( • (). التببؤ بكمية صادرات البطاطس المصرى لأهم الأسواق الأورويية حتى عام بr · r

\begin{tabular}{|c|c|c|c|c|c|}
\hline \multicolumn{5}{|c|}{ كمية صادرات البطاطس المصرى المرغوبة (ألف طن) } & \multirow{2}{*}{ السنة } \\
\hline هولندا & المملكة المتحدة & ألمانيا & اليونان & إيطاليا & \\
\hline 1.27 & 6.47 & 41.37 & 77.22 & 60.13 & 2020 \\
\hline 1.14 & 5.98 & 41.20 & 78.38 & 60.27 & 2021 \\
\hline 1.02 & 5.52 & 45.91 & 79.15 & 59.65 & 2022 \\
\hline 1.92 & 5.10 & 48.06 & 79.34 & 59.66 & 2023 \\
\hline-0.9 & -4.7 & 16.7 & -6.6 & -5.1 & مقدار التغير عن عام 2017 \\
\hline-32.4 & -47.9 & 53.3 & -7.7 & -7.9 & نسبة التغير عن عام 2017 \\
\hline 0.44 & 0.24 & 0.41 & 0.21 & 0.13 & Theil Inquality Test \\
\hline
\end{tabular}

المصدر: جمعت وحسبت من جدول (1) بالبحث.

المراجع

الجهاز المركزى للتعبئة العامة والإحصاء ،نشرة التجارة الخارجية ، أعداد متفرقة.

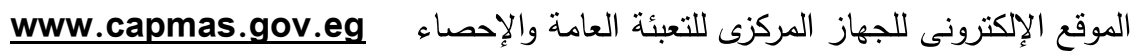

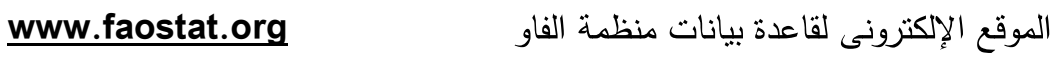

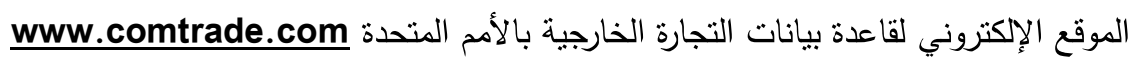

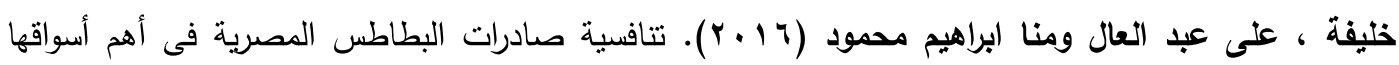

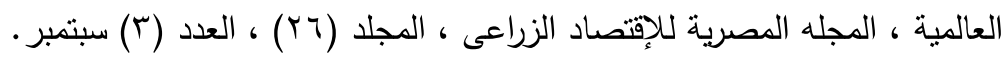

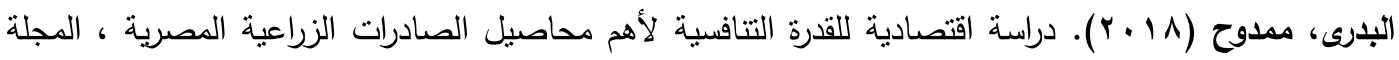

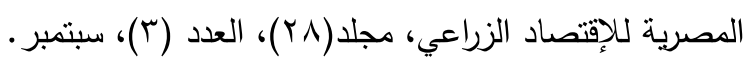

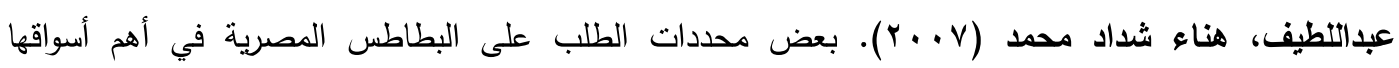

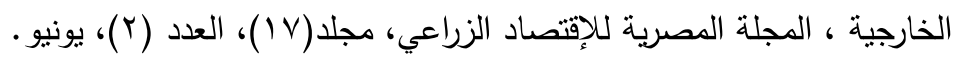


تصدير البطاطس المصرى ، يؤدي إلى تغير في عكس الإتجاه لصادرات البطاطس المصرى لسوق ألمانيا

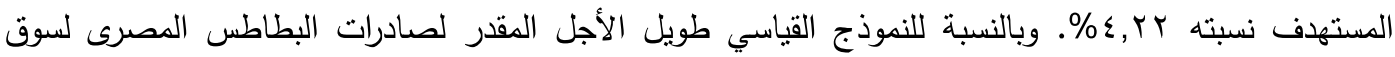
المملكة المتحدة فقد تبين أن أهم العوامل المحددة في المدى القصير والطويل تمثلت فى الإنتاج المحلى من البطاطس المصرى ، الإستهلاك المحلى من البطاطس المصرى ، حيث تبين من النموذج الإقتصادي القياسي طويل الأجل أن تغيراً نسبته ال الإنهاب في سعر تصدير البطاطس المصرى ، يؤدي إلى تغير في عكس الإتجاه

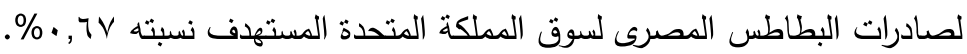
وبالنسبة للنموذج القياسي طويل الأجل المقدر لصادرات البطاطس المصرى لسوق هولندا فقد تبين أن أهم العوامل

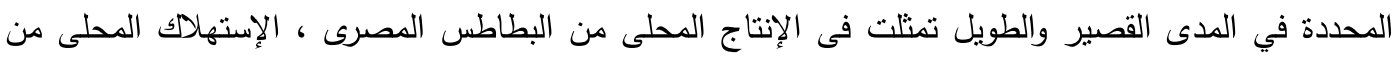

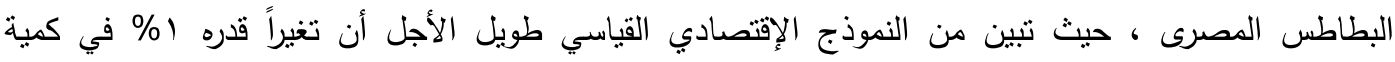
الإستهلاك المحلى من البطاطس المصرى ، يؤدي إلى تغير في عكس الإتجاه لصادرات البطاطس المصرى لسوق

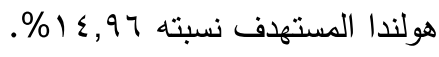

جدول (9). التقدير القياسى للمستوى المرغوب والمستهدف لصادرات البطاطس المصرى لأهم الأسواق

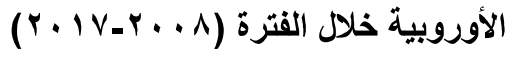

\begin{tabular}{|c|c|c|}
\hline الدالـــــة & النـــــوذج & السوق \\
\hline $\begin{array}{c}\log \hat{Y}_{t}=5.057+0.546 \log Y_{-1}+0.501 \log X_{1} \\
(4.51)^{* *} \\
F=25.5 \quad R^{-2}=0.731^{(5.05)^{* *}} \quad \text { D.W }=2.5 \\
(0.94)\end{array}$ & (لوغاريتمى مزدوج) الأساسى) & \multirow[t]{2}{*}{ إيطاليا } \\
\hline $\log \hat{Y}_{t}=11.139+1.104 \log X_{1}$ & 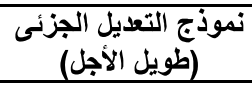 & \\
\hline $\begin{array}{c}\log \hat{Y}_{t}=5.814+0.46 \log Y_{-1}+0.21 \log X_{1} \\
\begin{array}{ccc}(2.47)^{*} & (2.01)^{*} & (0.81) \\
F=4.2 & R^{-2}=0.331 & \text { D.W }=2.4\end{array} \\
\end{array}$ & (لوغاريتمى مزدوج) الأساسى & \multirow[t]{2}{*}{ اليونان } \\
\hline $\log \hat{Y}_{t}=10.767+0.389 \log X_{1}$ & 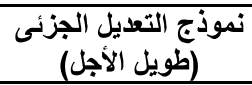 & \\
\hline $\begin{array}{c}\log \hat{Y}_{t}=30.33+0.177 \log Y_{-1}-3.475 \log X_{3} \\
\begin{array}{ccc}(5.05)^{\star *} & (0.17) & (-3.52)^{*} \\
F=12.4 \quad R^{-2}=0.558 & D . W=1.8\end{array}\end{array}$ & (لوغاريتمى مزدوج) الأساسى & \multirow[t]{2}{*}{ ألمانيا } \\
\hline $\log \hat{Y}_{t}=36.853-4.222 \log X_{3}$ & 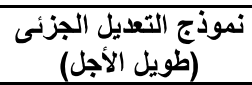 & \\
\hline $\begin{array}{c}\log \hat{Y}_{t}=5.29+0.603 \log Y_{-1}-0.266 \log X_{3} \\
(2.95)^{*}{ }^{*}(5.09)^{* *} \\
F=50.9 \quad R^{* 2}=0.917 \quad \text { D.W }{ }^{*}=2.6\end{array}$ & (لوغاريتمى مزدوج) & \multirow[t]{2}{*}{ المملكة المتحدة } \\
\hline $\log \hat{Y}_{t}=13.325-0.670 \log X_{3}$ & نموذج التعديل الجزئى & \\
\hline $\begin{array}{c}\log \hat{Y}_{t}=2.76+0.659 \log Y_{{ }^{-1}}-5.1 \log X_{2} \\
\begin{array}{ccc}(1.24) & (2.49) & (-1.76) \\
F=6.2 \quad R^{-2}=0.437 & D . W=1.7\end{array}\end{array}$ & (لوغاريتمى مزدوج) & \multirow[t]{2}{*}{ هولندا } \\
\hline $\log \hat{Y}_{t}=8.094-14.956 \log X_{2}$ & نموذج التعديل الجزئى & \\
\hline
\end{tabular}

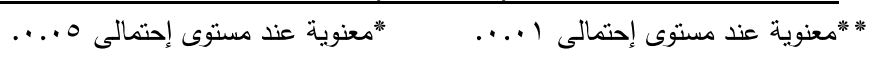

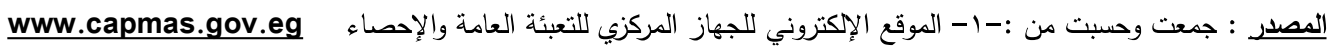

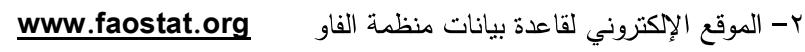


رابعاً :التقدير القياسي للمستوى المرغوب والمستهاف لصادرات البطاطس المصرى لأهم الأسواق الأوروبية:

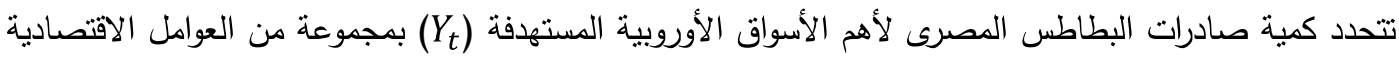

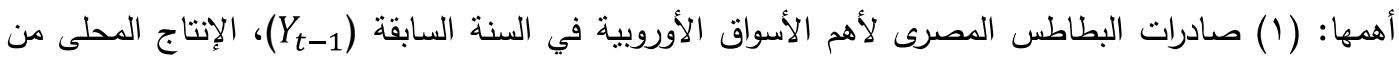

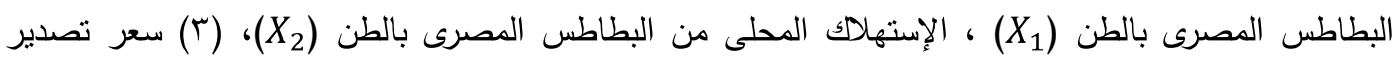

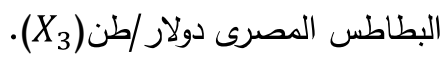

وبإجراء تحليل الانحدار المتعدد Multiple Regression Analysis للمتغيرات التفسيرية المحددة لصادرات

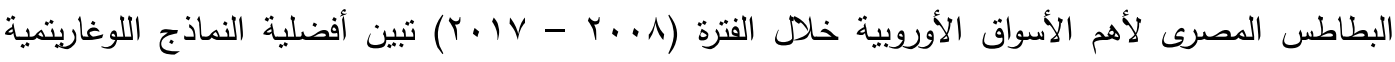

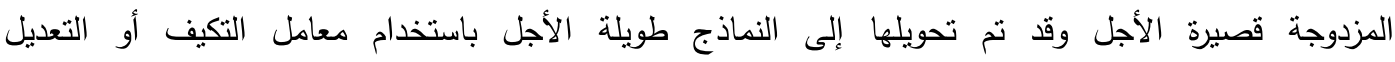
Adjustment Coefficient

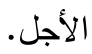

حيث تمثل $\lambda$ : معامل التعديل وتتراوح قيمته بين الصفر والواحد الصحيح، وتثير قيمتها القريية من الصفر إلى أن الن الصني

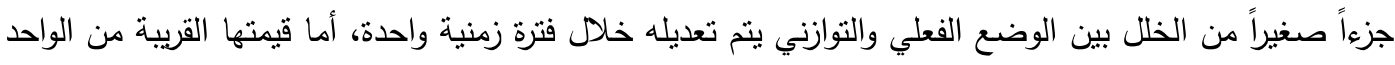

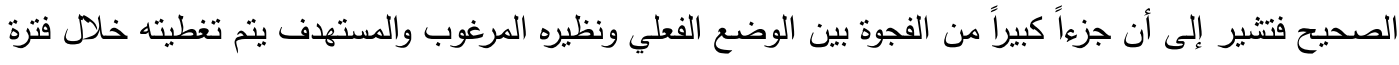

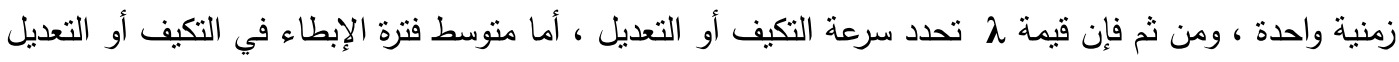
Adjustment Lag ويتضح من المعلمات Parameters المقدرة للنموذج القياسي المقدر لصادرات البطاطس المصرى لأهم الأسواق ،

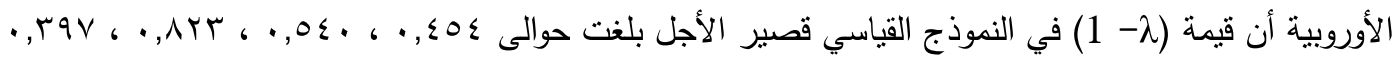

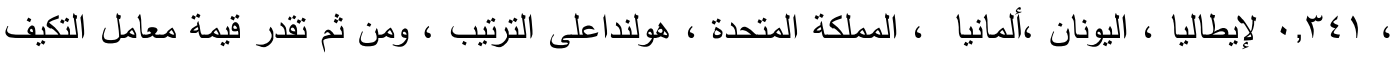

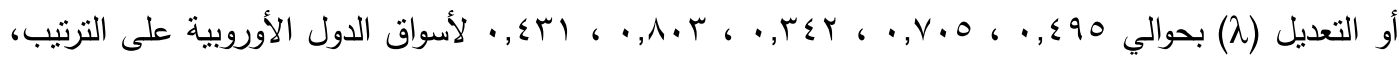

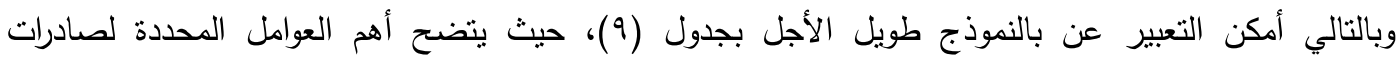

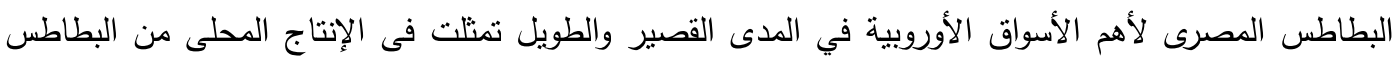

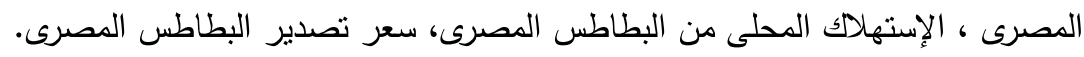

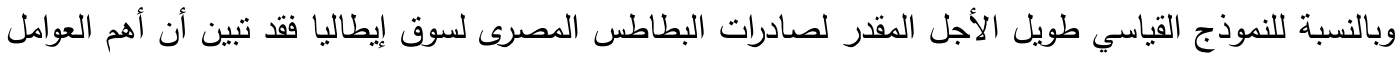

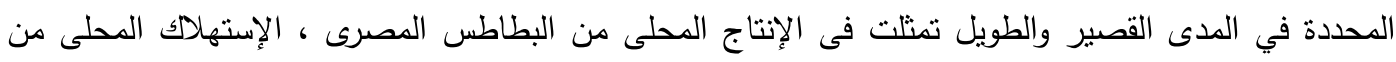

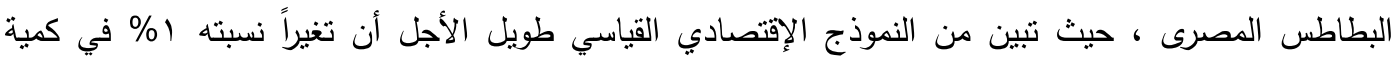

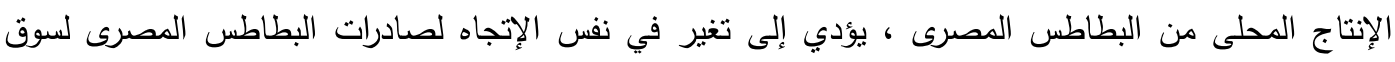

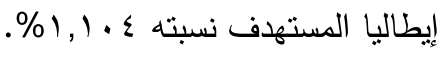
وبالنسبة للنموذج القياسي طويل الأجل المقدر لصادرات البطاطس الصصرى لسوق اليونان فقد تبين أن أهم العوامل

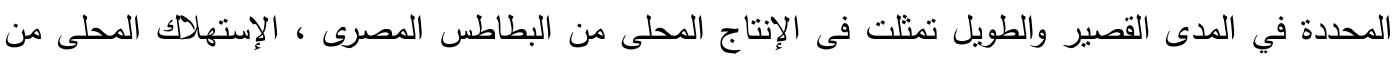

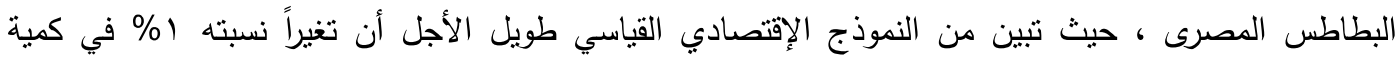

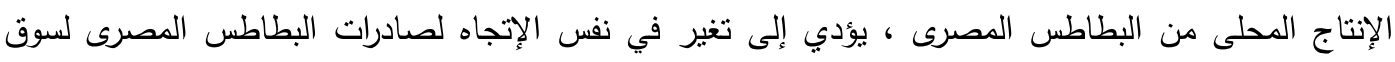

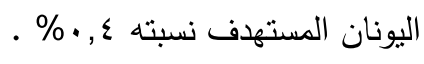

وبالنسبة للنموذج القياسي طويل الأجل الكقدر لصادرات البطاطس المصرى لسوق ألمانيا فقد تبين أن أهم العوامل

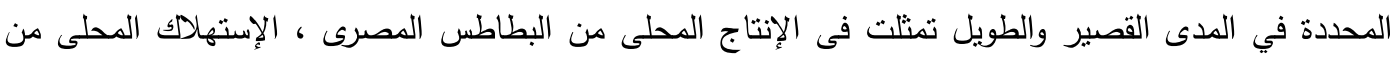

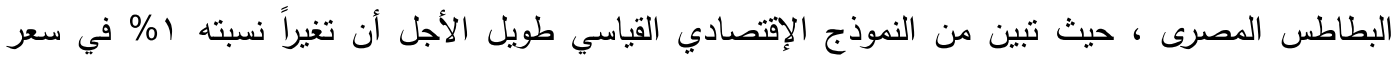


صادرات فرنسا من البطاطس لسوق ألمانيا (X5) حيث تبين أن تغيراً نسبته (\% في كل منهم يؤدى إلى انخفاض

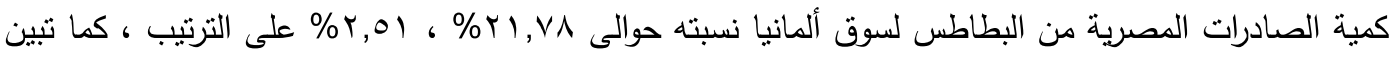

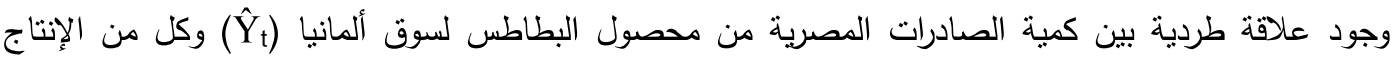

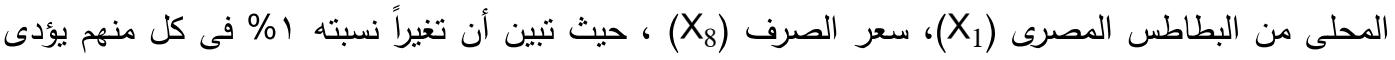

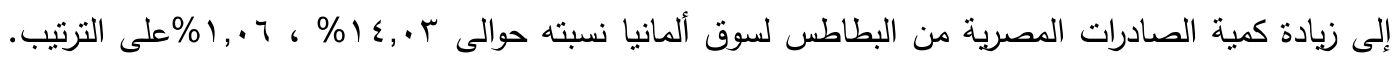
كما تبين أن تلك المتغيرات تفسر حوالى ه, •^^\% من التغيرات في كمية الصادرات المصرية من البطاطس لسوق

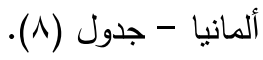
حيث تبين دن النموذج اللوغاريتمي المزدوج لسوق المملكة المتحدة وجود علاقة عكسية بين كمية الصادرات

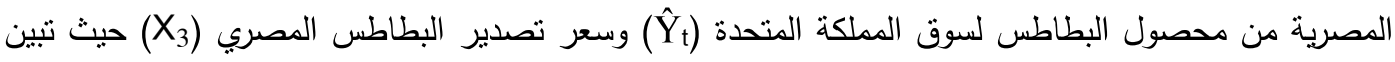
أن تغيراً نسبته (\% فئ سعر تصدير البطاطس المصري يؤدى إلى انخفاض كمية الصادرات المصرية من

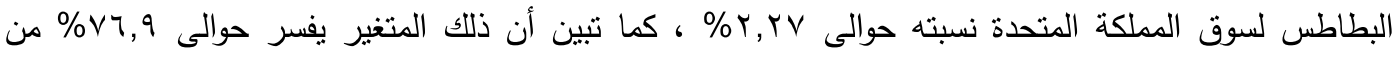
التغيرات في كمية الصادرات المصرية من البطاطس لسوق المملكة المتحدة - جدول (^).

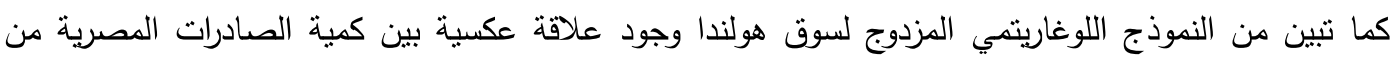
محصول البطاطس لسوق هولندا (X) ) وكمية الاستهلاك المحلى من البطاطس المصري (X2) حيث تبين أن تغيراً

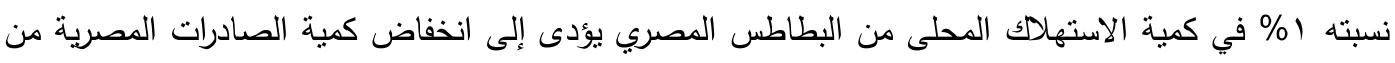

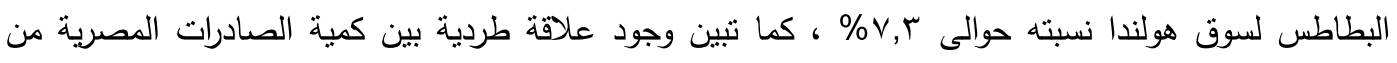

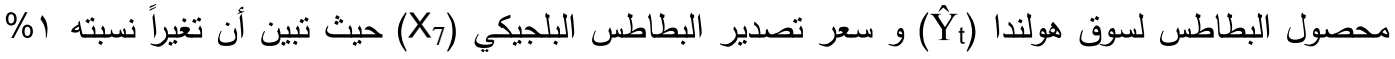
في سعر تصدير البطاطس البلجيكي يؤدى إلى زيادة كية الصادرات المصرية من البطاطس لسوق هولندا نسبته

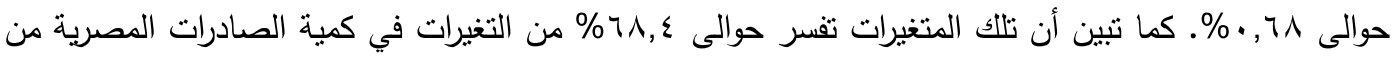
البطاطس لسوق هولندا - جدول (^).

جدول (^) ـ نتائج التقدير القياسى لاوال الطلب الخارجى لمحصول البطاطس التصديرى فى أهم أسواق الإتحاد

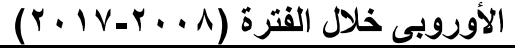

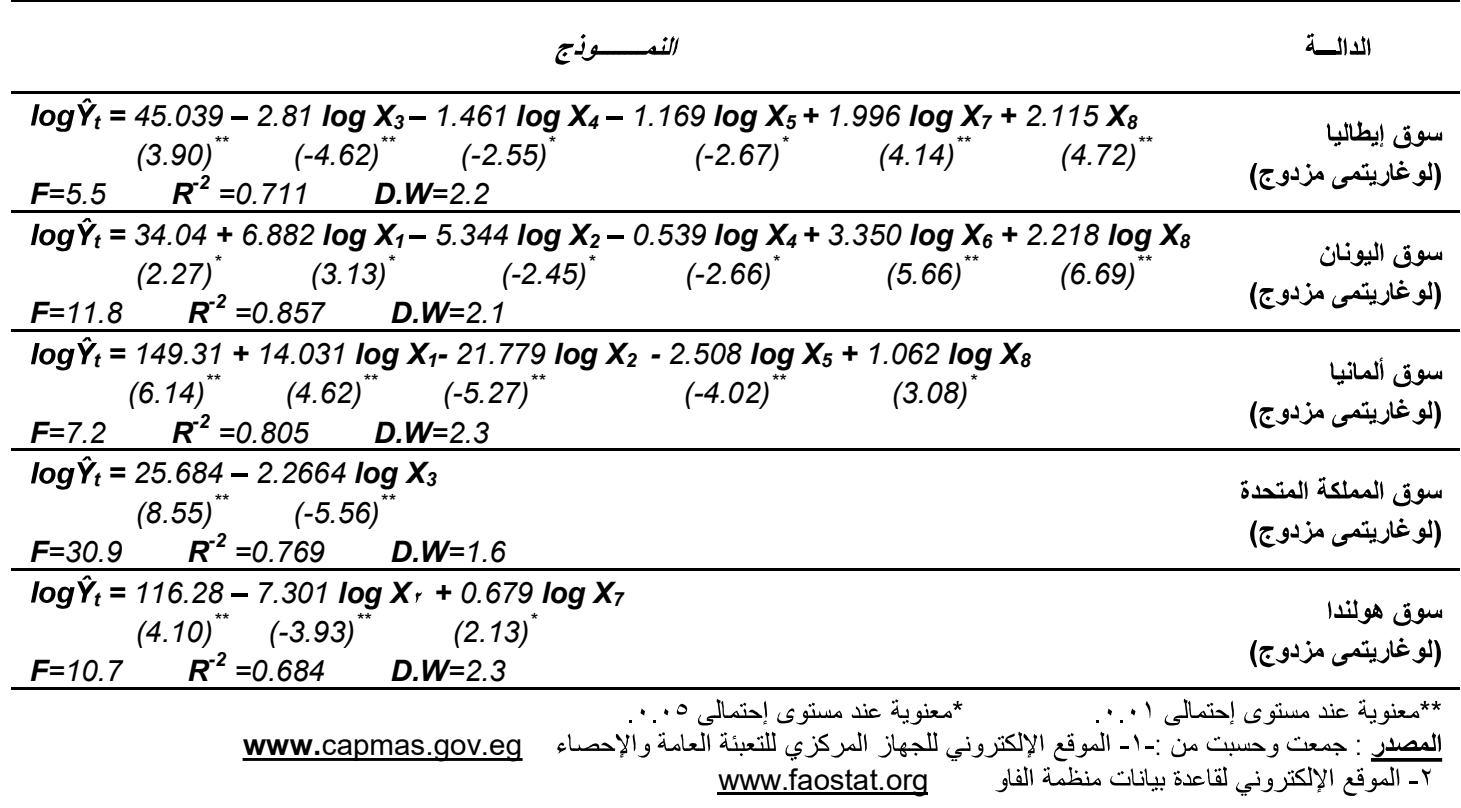


ثالثاً :التقدير القياسي لدوال الطب الخارجى لصادرات البطاطس المصرى فى أهم الأسواق الأورويية خلال الفترة $:(r+1 \vee-r \cdot \Lambda)$ تم إجراء التقدير القياسى لدوال الطلب الخارجى على محصول البطاطس المصرى فى أهم الأسواق الأوروبية

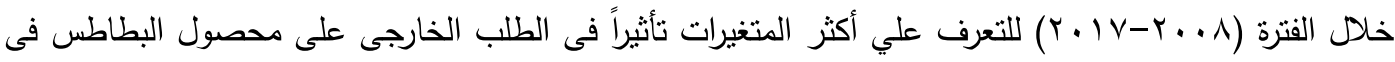
أهم الأسواق الأوروبية ، وذلك بعد استخدام الصور الرياضية المختلفة للاوال وهى الخطية والنصف لوغاريتمية

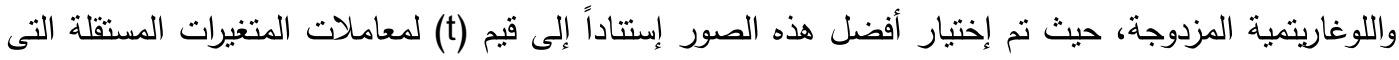

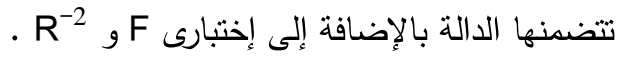
وتتطوي متغيرات دوال الطلب الخارجي على محصول البطاطس في أهم الأسواق الأوروبية على متغيراً تابعاً تمثل

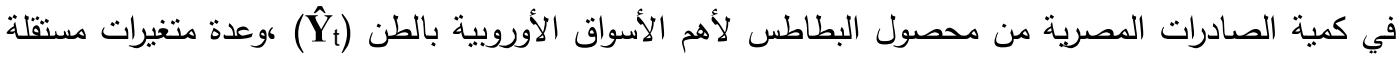

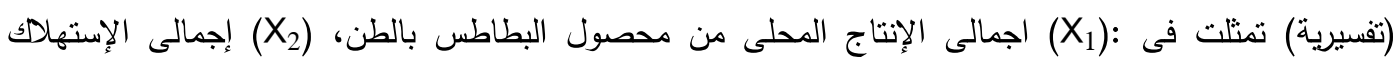

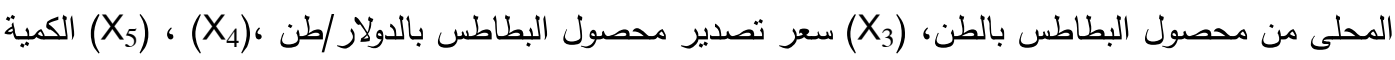
المصدرة من محصول البطاطس لأهم الأسواق المنافسة بالطن (X) (X) (X) بعر تصدير أهم سوقين منافسين لمحصول البطاطس المصرى بالدولار/طن، (X8) سعر الصرف الرسمى بالجنيه/دولار .

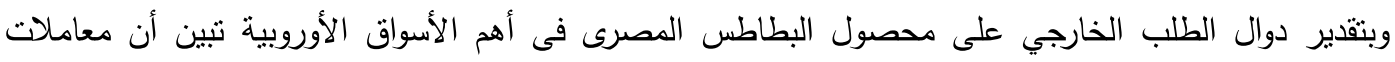

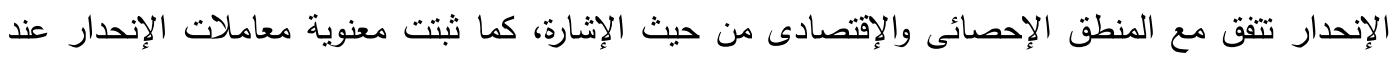

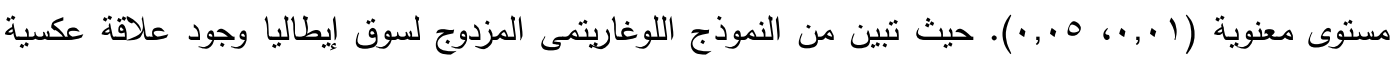

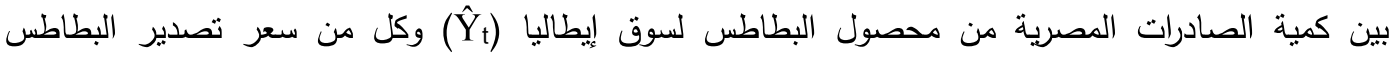

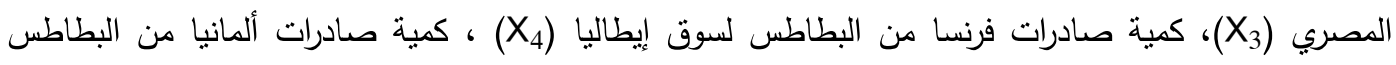

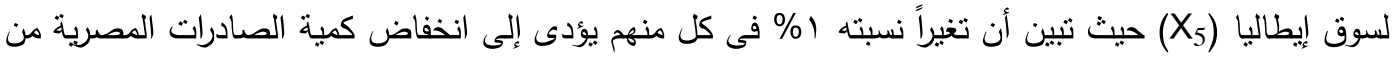

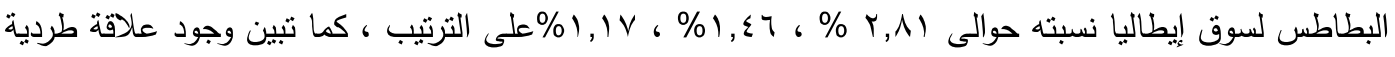

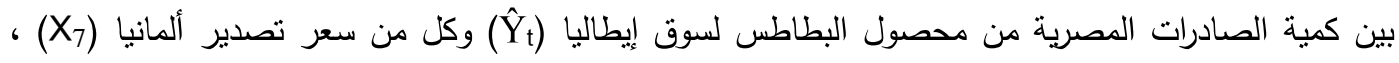
سعر الصرف (X8)، حيث تبين أن تغيراً نسبته (\% ( في كل منهم يؤدى إلى زيادة كمية الصادرات المصرية من

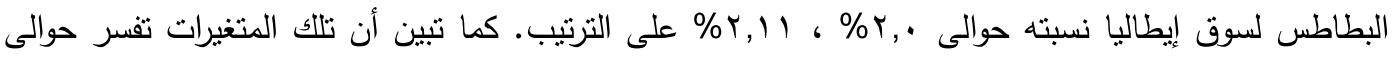

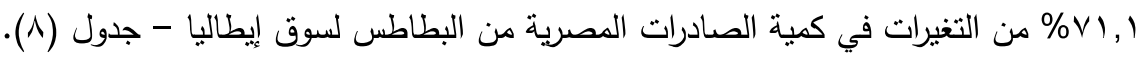

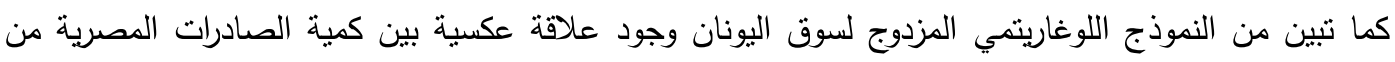

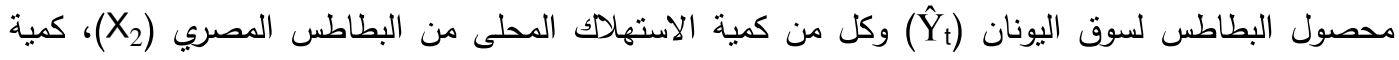

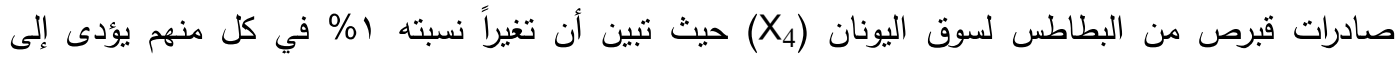

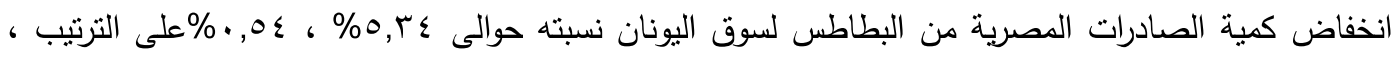

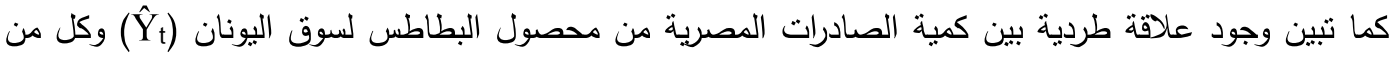

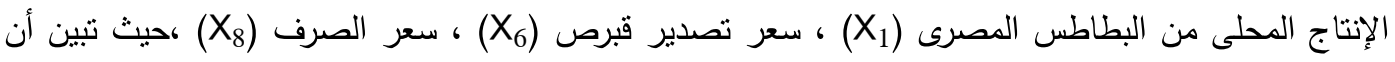

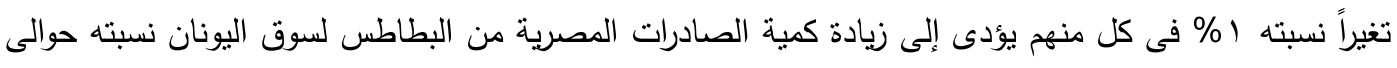

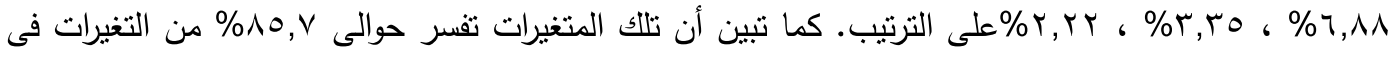

كمية الصادرات الدصرية من البطاطس لسوق اليونان - جدول (^).

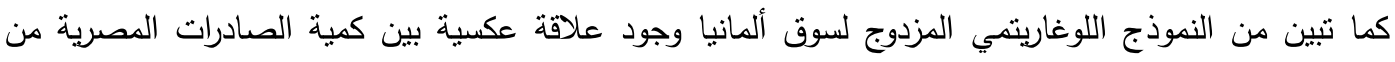

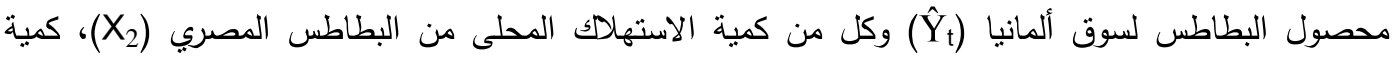


ع-المؤثر المركب للتنافسية لصادرات محصول البطاطس المصرى فى أهم الأسواق الأورويية خلال الفترة $:(r+\mid \gamma-r+\Lambda)$

يعكس المؤشر المركب للتنافسية مدى تتافس الدولة فى الأسواق الخارجية ، وهو عبارة عن متوسط مجموع

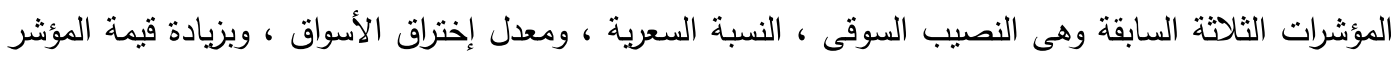
فيدل ذلك على تمتع الدولة بموقع متقدم مقارنة بالدول المنافسة والعكس صحيح. ويأخذ المعادلة التالية: $\mathrm{CICj}=(\mathrm{M} . \mathrm{S}+\mathrm{PRI}+\mathrm{MPRij}) / 3$

$$
\begin{aligned}
& \text { CICj } \\
& \text { M.S مؤشر النصيب السوقى. : } \\
& \text { : مؤشر النسبة السعرية (المركز التتافسى). } \\
& \text { MPRij }
\end{aligned}
$$

حيث تبين من بيانات جدول (V) أن المؤشر المركب للتنافسية لصادرات محصول البطاطس المصري في أهم

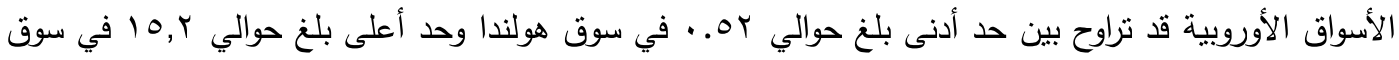

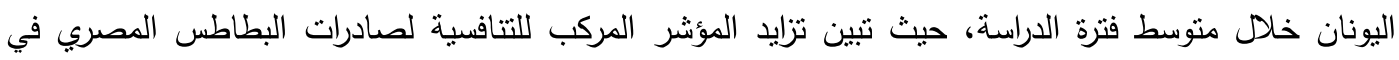

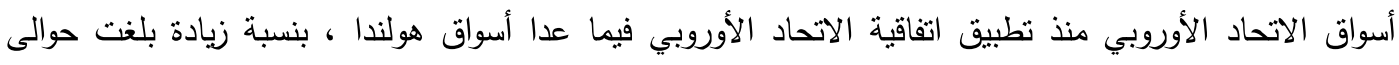

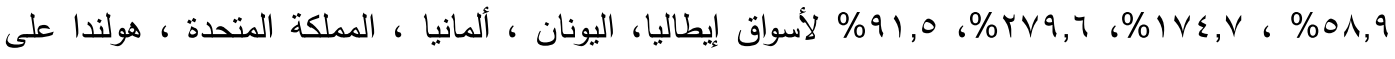

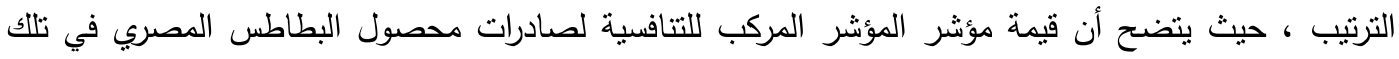
الأسواق الأوروبية قد زادت عن الواحد الصحيح مما يعني تمتع مصر بميزة تتافسية مقارنة بالأسواق المنافسة في

\begin{tabular}{|c|c|c|c|c|c|}
\hline هولندا & الملكة المتحدة & المسانيا & اليونان & ايطاليـا & السنة \\
\hline 0.58 & 1.7 & 1.2 & 13.7 & 8.1 & 2008 \\
\hline 1.00 & 2.2 & 3.7 & 12.5 & 3.8 & 2009 \\
\hline 1.01 & 2.7 & 2.3 & 14.8 & 4.7 & 2010 \\
\hline 0.57 & 3.3 & 2.0 & 10.8 & 5.7 & 2011 \\
\hline 0.73 & 1.2 & 3.3 & 11.3 & 3.7 & 2012 \\
\hline 0.34 & 2.2 & 0.9 & 11.2 & 6.4 & 2013 \\
\hline 0.32 & 2.1 & 2.2 & 6.9 & 6.1 & 2014 \\
\hline 0.18 & 1.3 & 1.6 & 17.1 & 7.1 & 2015 \\
\hline 0.19 & 2.0 & 3.2 & 15.6 & 7.2 & 2016 \\
\hline 0.32 & 3.3 & 4.5 & 37.7 & 12.9 & 2017 \\
\hline 0.52 & 2.2 & 2.5 & 15.2 & 6.6 & المتوسط \\
\hline
\end{tabular}
أسواق تلأك الدول خلال فترة الدراسة.

جدول (V). تطور المؤشر المركب لتنافسية صادرات محصول البطاطس لأهم الأسواق الأوروبية خلال الفترة $(r+1 v-r+\lambda)$

www.capmas.gov.eg المصدر : جمعت وحسبت من : المبول الموقع الإكتروني للجهاز المركزي للتعبئة العامة والإحصاء

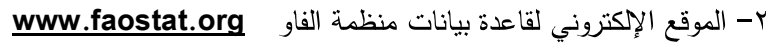




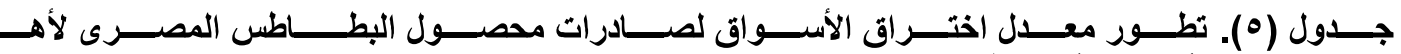

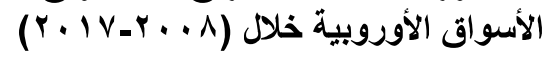

\begin{tabular}{|c|c|c|c|c|c|}
\hline هولندا & المملكة المتحدة & المسانيا & اليونان & ابطاليا & السنة \\
\hline 0.11 & 0.30 & 0.13 & 6.59 & 4.72 & 2008 \\
\hline 0.13 & 0.22 & 0.38 & 4.20 & 1.42 & 2009 \\
\hline 0.20 & 0.28 & 0.33 & 5.84 & 2.97 & 2010 \\
\hline 0.15 & 0.39 & 0.33 & 5.72 & 3.42 & 2011 \\
\hline 0.21 & 0.20 & 0.46 & 3.81 & 2.02 & 2012 \\
\hline 0.06 & 0.51 & 0.17 & 4.75 & 4.53 & 2013 \\
\hline 0.04 & 0.19 & 0.24 & 2.86 & 2.98 & 2014 \\
\hline 0.00 & 0.11 & 0.18 & 7.92 & 3.67 & 2015 \\
\hline 0.01 & 0.17 & 0.30 & 6.56 & 3.30 & 2016 \\
\hline 0.04 & 0.16 & 0.30 & 12.80 & 3.65 & 2017 \\
\hline 0.06 & 0.23 & 0.26 & 5.6 & 3.10 & المتوسط \\
\hline
\end{tabular}

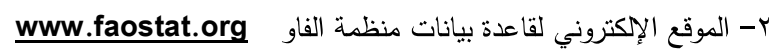

r- مؤثر النسبة السعرية لصادرات البطاطس المصرى فى أهم الأسواق الأورويية خلال الفترة

$$
:(r+1 v-r+\Lambda)
$$

ويحسب من خلال قسمة سعر تصدير الدول المنافسة من محصول ما/سعر تصدير مصر لنفس المحصول. وإذا زادت قيمة هذا المؤشر عن الواحد الصحيح دل ذلك على أن لمصر ميزة تتافسية سعرية فى تصدير هذا المحصول والعكس صحيح. حيث تبين من بيانات جدول (7) إرتفاع مؤشر النسبة السعرية لمحصول البطاطس بالمقارنة

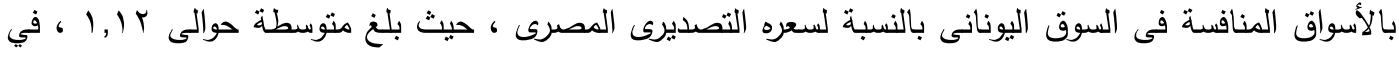
حين تبين إنخفاض مؤشر النسبة السعرية لمحصول البطاطس بالمقارنة بالأسواق المنافسة فى أسواق إيطاليا ، ألمانيا، المملكة المتحدة ، هولندا على الترتيب بالنسبة لسعره التصديرى المصرى ، حيث بلغ متوسطه فى تلك لتك

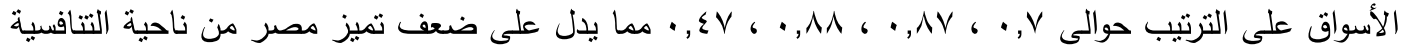

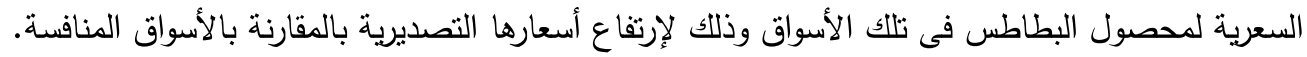

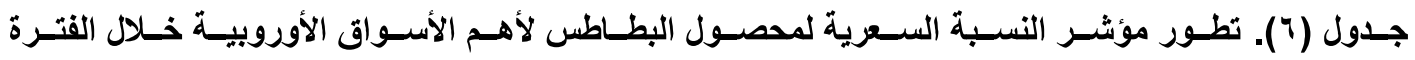
$(r+1 V-r+\lambda)$

\begin{tabular}{|c|c|c|c|c|c|}
\hline هولندا & المملكة المتحدة & المـانيا & اليونان & ايطاليـا & السنة \\
\hline 0.58 & 1.03 & 1.49 & 1.61 & 0.93 & 2008 \\
\hline 0.45 & 0.98 & 0.79 & 0.94 & 0.61 & 2009 \\
\hline 0.44 & 1.06 & 1.07 & 1.45 & 0.93 & 2010 \\
\hline 0.72 & 1.22 & 1.48 & 1.86 & 0.97 & 2011 \\
\hline 0.55 & 1.01 & 0.64 & 1.18 & 0.81 & 2012 \\
\hline 0.59 & 1.01 & 0.99 & 1.41 & 0.94 & 2013 \\
\hline 0.47 & 0.91 & 0.89 & 1.17 & 0.68 & 2014 \\
\hline 0.50 & 0.80 & 1.07 & 1.03 & 0.68 & 2015 \\
\hline 0.46 & 0.76 & 0.70 & 0.80 & 0.59 & 2016 \\
\hline 0.24 & 0.52 & 0.47 & 0.55 & 0.34 & 2017 \\
\hline 0.47 & 0.88 & 0.87 & 1.12 & 0.70 & لمتوسط \\
\hline
\end{tabular}

www.capmas.gov.eg المصدر : جمعت وحسبت من :- إ- الموقع الإكتروني للجهاز المركزي للتعبئة العامة والإحصاء بww.faostat.org ب الموقع الإكتروني لقاعدة بيانات منظمة الفاو 


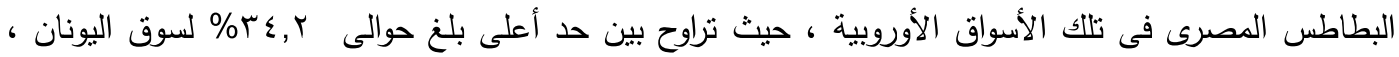

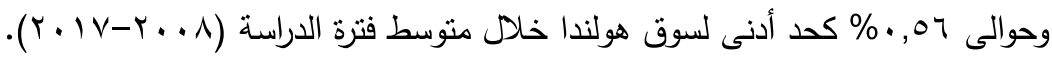

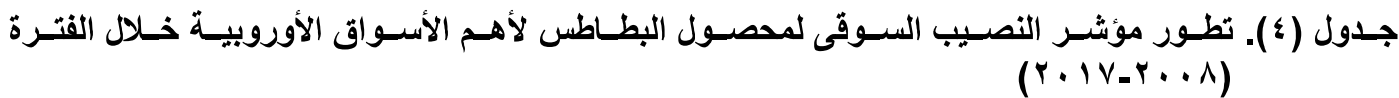

\begin{tabular}{|c|c|c|c|c|c|}
\hline هولندا & المملكة المتحدة & المـاتيا & اليونان & ايطاليـ & السنة \\
\hline 1.04 & 3.8 & 1.9 & 33.0 & 18.7 & 2008 \\
\hline 2.42 & 5.3 & 10.0 & 32.5 & 9.5 & 2009 \\
\hline 2.40 & 6.8 & 5.4 & 37.2 & 10.1 & 2010 \\
\hline 0.85 & 8.3 & 4.2 & 24.8 & 12.8 & 2011 \\
\hline 1.43 & 2.3 & 8.7 & 28.9 & 8.2 & 2012 \\
\hline 0.39 & 5.1 & 1.5 & 27.4 & 13.7 & 2013 \\
\hline 0.45 & 5.1 & 5.5 & 16.6 & 14.5 & 2014 \\
\hline 0.04 & 3.1 & 3.5 & 42.4 & 17.0 & 2015 \\
\hline 0.09 & 4.9 & 8.5 & 39.4 & 17.8 & 2016 \\
\hline 0.68 & 9.1 & 12.7 & 99.9 & 34.7 & 2017 \\
\hline 0.56 & 5.0 & 5.1 & 34.2 & 14.4 & المتوسط \\
\hline
\end{tabular}

www.capmas.gov.eg المصدر : جمعت وحسبت من :-1- الموقع الإكتروني للجهاز المركزي للتعبئة العامة والإحصاء

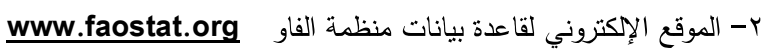

r-مؤشر معدل إخترق الأسواق Market Penetration Indictor نصادرات البطاطس المصرى فى أهم

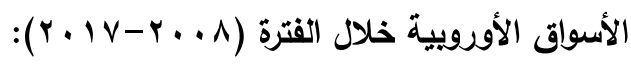

يقيس المؤشر قدرة محصول أو سلعة معينة على اختراق أسواق تصديرية معينة ، وكلما ارتفعت قيمة مؤشر إختراق

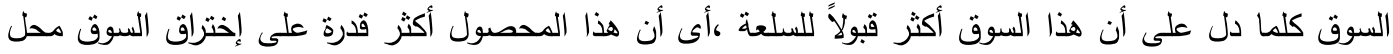
الدراسة، ويقاس بالمعادلة التالية:

$$
M P R_{i j}=\left[M_{i j t} /\left(Q_{i j}+M_{i j}-X_{i j}\right)\right]
$$

حيث أن:

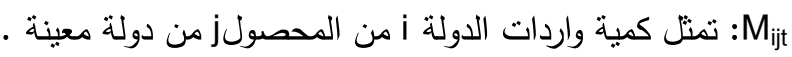

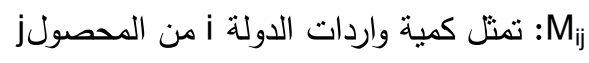

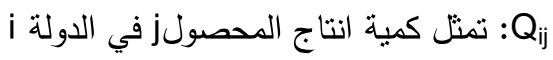

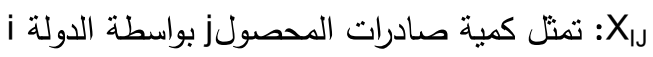

ويتضح من دراسة الجدول رقم (0) أن سوق اليونان هو أكبر الأسواق التى يخترقها البطاطس المصرى بحوالى

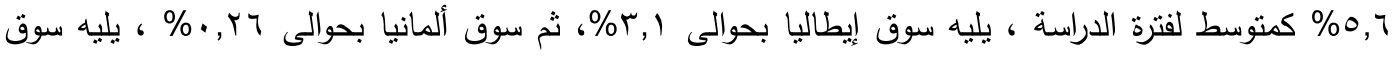

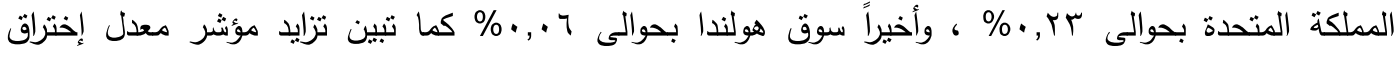

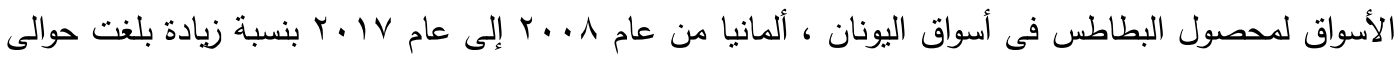

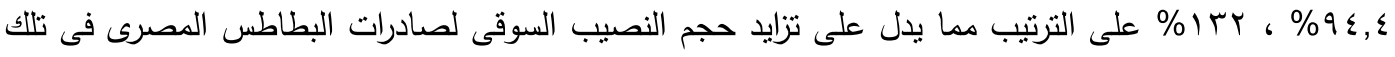
الأسواق الأوروبية ، فى حين تبين إنخفاض قيمة المؤشر فى أسواق إيطاليا، المملكة المتحدة ، هولندا بنسبة

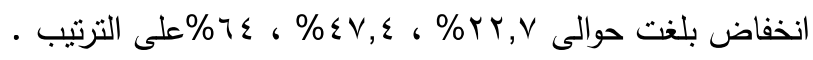


: ت تمثل معامل التزكز الجغرافي لكمية وقيمة الصادرات المصرية من المحصول.

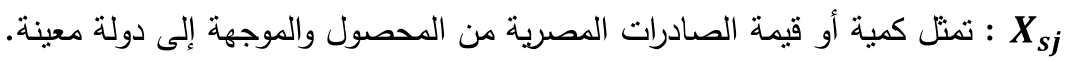

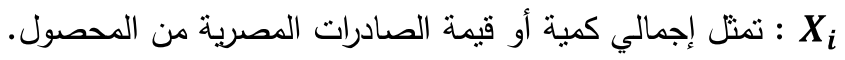

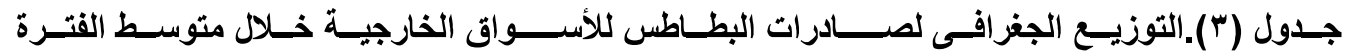

$$
\begin{aligned}
& \left(r+1 V_{-} r+. \wedge\right)
\end{aligned}
$$

\begin{tabular}{|c|c|c|c|c|c|}
\hline (السعر التصديرى & $\%$ & قالبطة صادرات & $\%$ & كمبة صادرات & الدولة \\
\hline 412.8 & 34.14 & 72.13 & 36.46 & 174.76 & روسيا الأتحاديه \\
\hline 440.1 & 12.74 & 26.91 & 12.75 & 61.14 & إيطاليا \\
\hline 437.7 & 10.59 & 22.38 & 10.67 & 51.13 & الثيونـان \\
\hline 428.5 & 8.25 & 17.43 & 8.49 & 40.68 & البنان \\
\hline 464.3 & 6.12 & 12.92 & 5.81 & 27.83 & المـانيا \\
\hline 530.8 & 5.31 & 11.22 & 4.41 & 21.13 & الإمارات \\
\hline 545.2 & 4.78 & 10.10 & 3.87 & 18.53 & ألكويت \\
\hline 512.7 & 3.64 & $\begin{array}{l}7.69 \\
7.69\end{array}$ & 3.13 & 15.00 & المملكة المتحدة \\
\hline 443.3 & 2.57 & 5.44 & 2.56 & 12.26 & سوريا \\
\hline 526.4 & 1.89 & 4.00 & 1.58 & 7.59 & عمـان \\
\hline 573.4 & 1.18 & 2.48 & 0.90 & 4.33 & قطر \\
\hline 307.0 & 1.17 & 2.46 & 1.67 & 8.03 & أوكرانيا \\
\hline 381.1 & 1.15 & 2.42 & 1.33 & 6.36 & هولثندا \\
\hline 648.1 & 1.07 & 2.27 & 0.73 & 3.50 & إندونيسيا \\
\hline 374.1 & 0.66 & 1.39 & 0.77 & 3.71 & العراق \\
\hline 444.2 & 0.65 & 1.38 & 0.65 & 3.11 & تونس \\
\hline 434.2 & 0.52 & 1.11 & 0.53 & 2.55 & رومانيّا \\
\hline 425.1 & 3.56 & 7.53 & 3.70 & 17.71 & أخرى \\
\hline \multirow[t]{2}{*}{462.7} & 100 & 211.3 & 100 & 479.4 & الجملة \\
\hline & & 0.40 & & 0.42 & عامل التركز الجغرافي \\
\hline
\end{tabular}

www.trademap.org الموقع الإكتروني لخريطة التجارة الخارجية

ثانياً :مؤُشرات الققرة التنافسية للصادرات المصرية من محصول البطاطس فى أهم الأسواق الأوروبية: يتناول هذا الجزء قياس القدرة التتافسية للصادرات المصرية من محصول البطاطس فى أهم الأسواق الأوروبية من

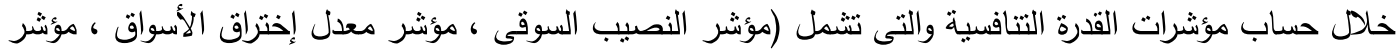
النسبة السعرية، المؤشر المركب للتنافسية) . ا-مؤثش النصيب السوقي لصادرات البطاطس المصري فى أهم الأسواق الأوروبية خلال الفترة (^...r$:(r \cdot l v$

يحسب مؤثر النصيب السوقي من خلال قسمة قيمة صادرات الدولة من سلعة معينة إلى إجمالي قيمة الصادرات

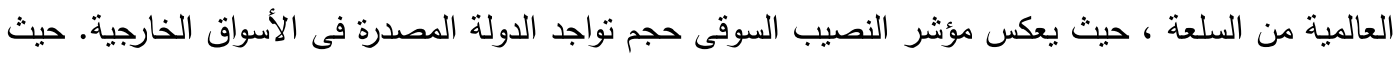

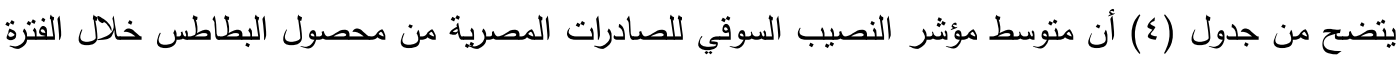

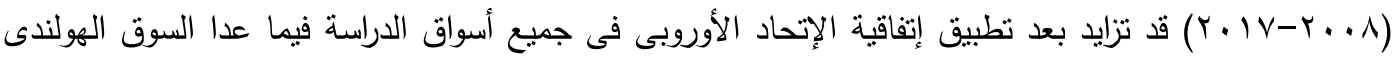

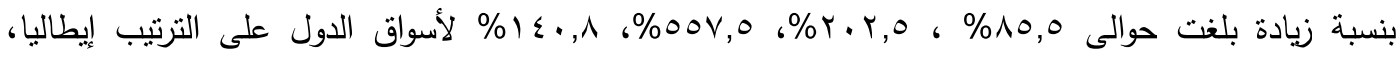

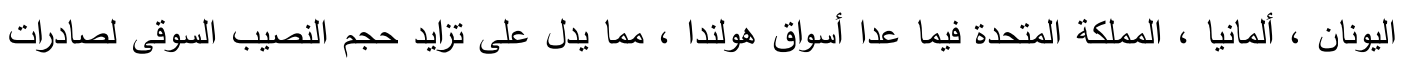




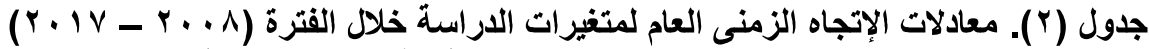
(الكمية : ألف طن - القيمة :مليون دولار- السعر : دولار/طن)

\begin{tabular}{|c|c|c|c|c|c|}
\hline المتوسط & معدل النمو & $\mathbf{F}$ & $\mathbf{R}^{2}$ & المعــادلــة & ال المتغير \\
\hline 771.9 & 1.3 & $4.9^{*}$ & 0.38 & $\begin{array}{c}\hat{\mathrm{Y}}_{\mathrm{t}}=708.3+10.11 X_{t} \\
(2.21)^{*}\end{array}$ & قالمصرية لدادرل الإتحاد الأوروبي \\
\hline 479.4 & 9.2 & $6.6^{*}$ & 0.451 & $\begin{array}{c}\hat{\mathrm{Y}}_{\mathrm{t}}=236.18+44.21 X_{t} \\
(2.56)^{*}\end{array}$ & كمية صادرات البطاطس \\
\hline 200.1 & ^.乏 & $9.1^{* *}$ & 0.533 & $\begin{array}{r}\hat{\mathrm{Y}}_{\mathrm{t}}=114.48+16.84 X_{t} \\
(3.02)^{* *}\end{array}$ & قيمة صادرات البطاطس \\
\hline 438.7 & -2.5 & $5.3^{* *}$ & 0.397 & $\begin{array}{c}\hat{\mathrm{Y}}_{\mathrm{t}}=479.66-11.08 X_{t} \\
(-2.30)^{*}\end{array}$ & سعر تصدير البطاطس \\
\hline
\end{tabular}

المصدر : جمعت وحسبت من بيانات جدول (1). **معنوية عند مستوى احتمالي ا .... "معنوية عند مستوى إحتمالى ه....

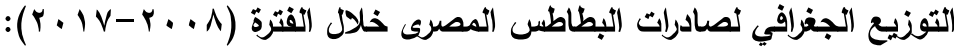

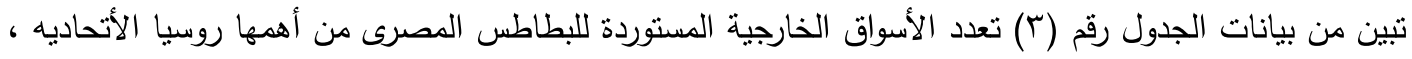

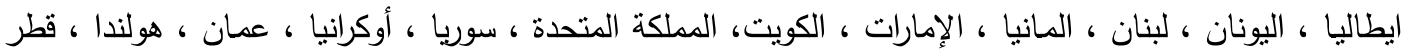
، العراق ، إندونسيا ، تونس ، رومانيا. وبدراسة التوزيع الجغرافي لكمية صادرات محصول البطاطس المصرى فى لق

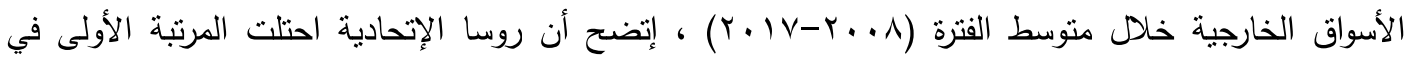
واردات البطاطس المصرية حيث بلغ متوسط كميته حوالى VY,V7 V7 ألف طن تمثل حوالى 9 ع, بr\% من متوسط

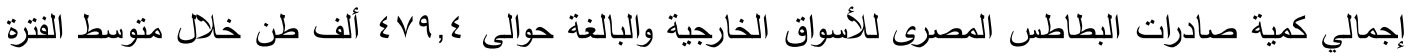
$\cdot(r \cdot \mid V-r \cdot \cdot \Lambda)$

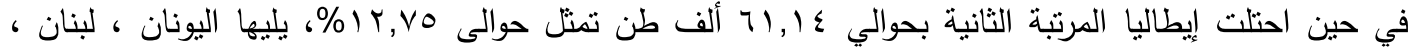

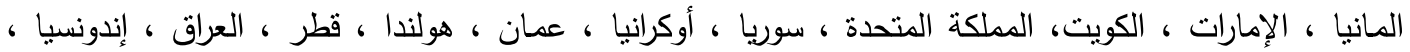

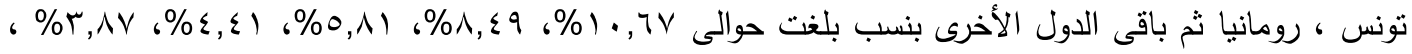

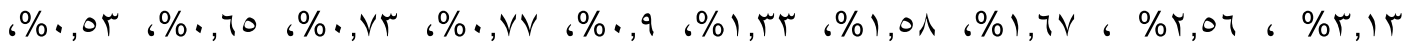

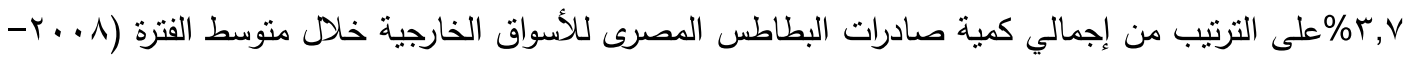

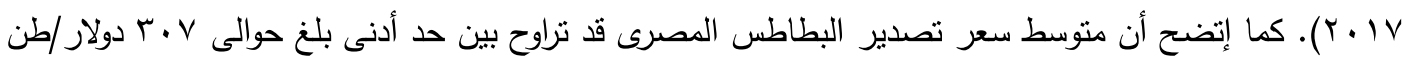

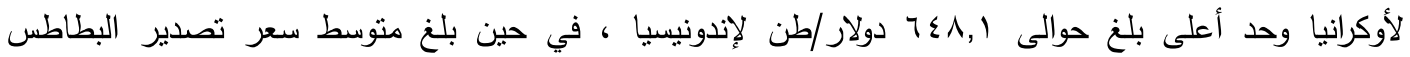

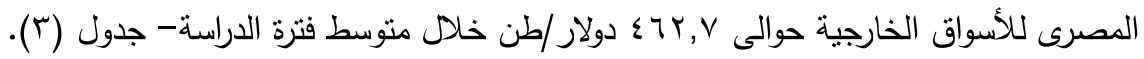
وقد تم حساب التركز الجغرافى لكمية وقيمة الصادرات المصرية من محصول البطاطس بإستخدام معامل جينىـ هيرشمان ، حيث تتراواح قيمة المؤشر بين الصفر والواحد الصحيح فكلما إقتربت قيمة المعامل من الواحد الصحيح

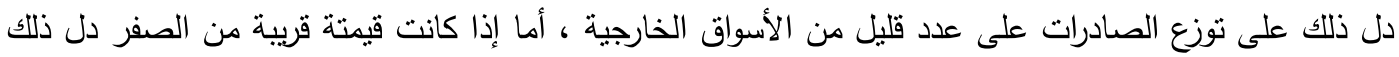

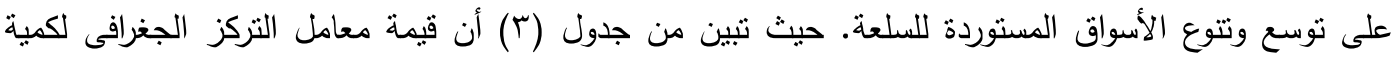
وقيمة الصادرات الدصرية من محصول البطاطس قد بلغت حوالى بـ , ،، ، ع, · على الترتيب وبذلك يعتبر معامل التركز الجغرافي منخفض نسبياً وهو مايعكس تعدد الأسواق الخارجية لصادرات البطاطس المصرية خلادل متوسط

$$
{ }^{*} C_{j x}=100 \sqrt{\Sigma{\frac{\left(X_{s j}\right)^{2}}{\left(X_{i}\right)^{2}}}^{2}}
$$


النتائج البحثية وإلمناقشة

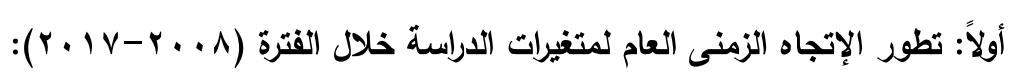

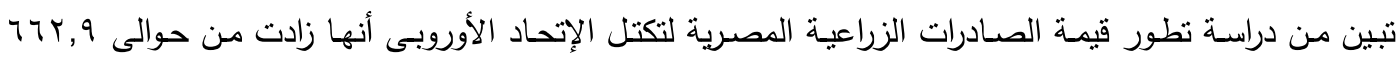

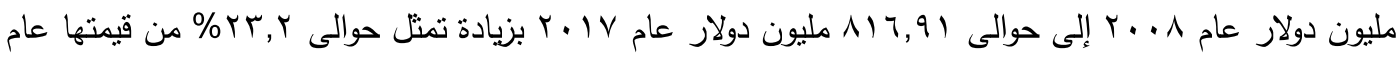

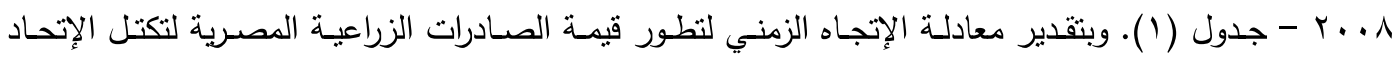

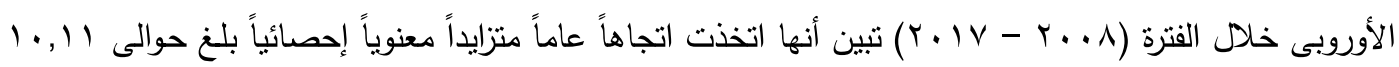

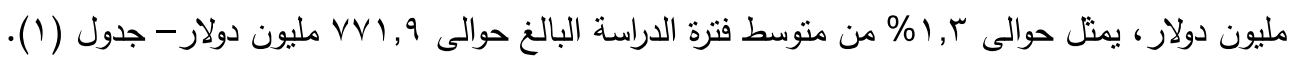

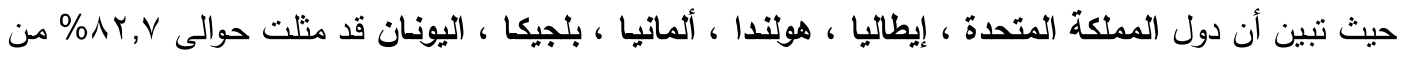

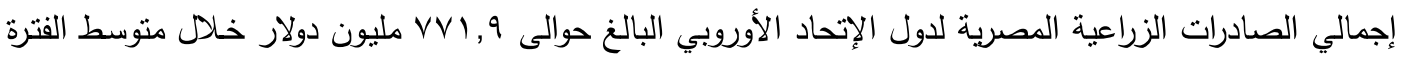

$$
\text { · }(r \cdot 1 V-r \cdot \cdot \Lambda)
$$

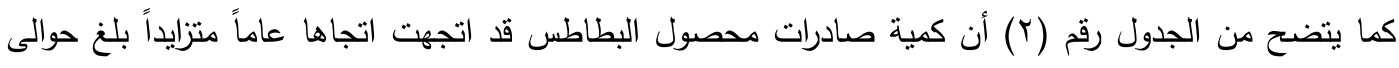

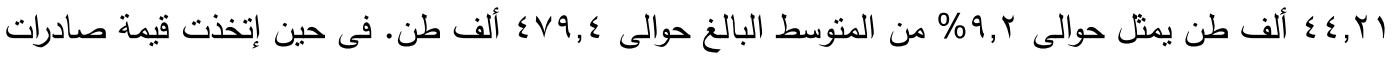

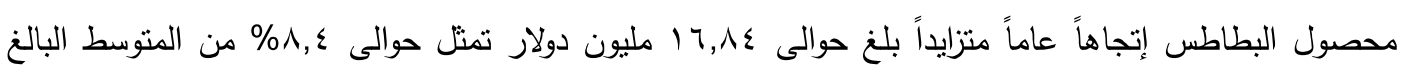

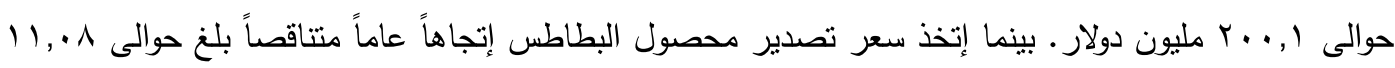

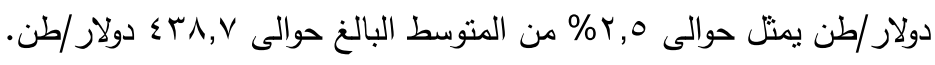

جدول (1). تطور قيمة الصادرات الزراعية المصرية لدول الإتحاد الأوروبى بالمليون دولار خلال متوسط الفترة

\begin{tabular}{|c|c|c|c|c|}
\hline \multicolumn{3}{|c|}{ 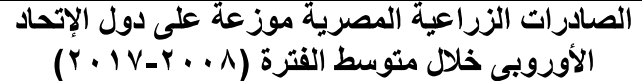 } & \multirow{2}{*}{ قيمه الصادرات الزراعية } & \multirow[t]{2}{*}{ السنة } \\
\hline$\%$ & مليون دولار & الاولة & & \\
\hline 22.7 & 175.0 & المملكه المتحده & 662.9 & 2008 \\
\hline 18.6 & 143.6 & ايطاليا & 836.6 & 2009 \\
\hline 15.5 & 119.4 & هولندا & 772.8 & 2010 \\
\hline 14.1 & 108.6 & المانيا & 787.0 & 2011 \\
\hline 7.7 & 59.2 & بلجيكا & 731.5 & 2012 \\
\hline 4.1 & 31.3 & اليونان & 816.4 & 2013 \\
\hline 3.7 & 28.9 & فرنسا & 796.8 & 2014 \\
\hline 2.3 & 18.1 & اسباتيا & 720.1 & 2015 \\
\hline 2.0 & 15.6 & رومانيا & 778.2 & 2016 \\
\hline 9.3 & 72.2 & باقى الدول & 816.9 & 2017 \\
\hline 100 & 771.9 & الجملة & 771.9 & المتوسط \\
\hline
\end{tabular}
$(r+1 V-r+1)$

المصدر : جمعت وحسبت من : ا-الجهاز المركزى للتعبئة العامة والإحصاء ،نشرة التجارة الخارجية ، أعداد متفرقة.

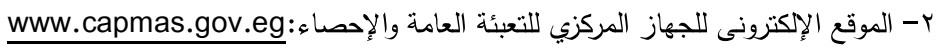


ع - قياس محددات دالة الطلب الخارجي على صادرات محصول البطاطس فى أهم أسواق الإتحاد الأوروبى خلال

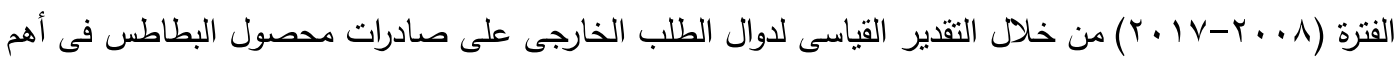

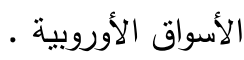
0- التقدير القياسى للمستوى المرغوب والمستهدف لصادرات البطاطس المصرى فى أهم الأسواق الأوروبية. Y- دراسة مستقبل صادرات محصول البطاطس فى أهم أسواق الإتحاد الأوروبى حتى عام بr • ب.

\section{الأسلوب البحثي ومصادر البيانات}

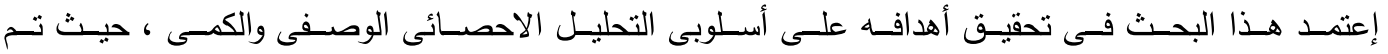

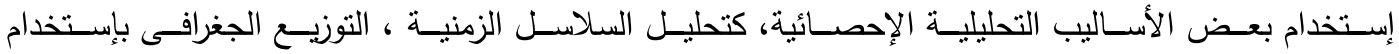

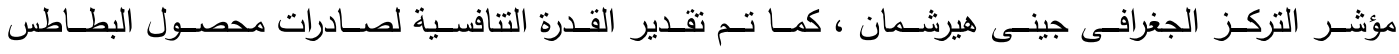

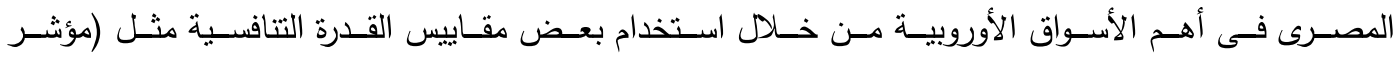

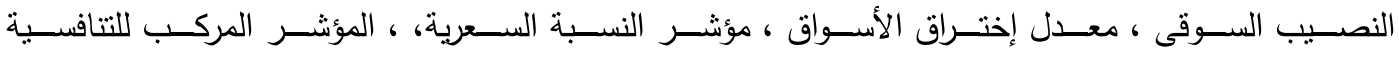

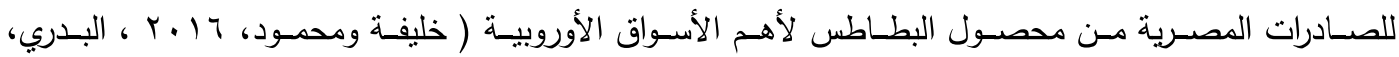
$\cdot(r \cdot) 1$ كما تم استخدم أسلوب تحليل الانحدار المرحلى لتقدير دالة الطلب الخارجى على كمية الصادرات المصرية من

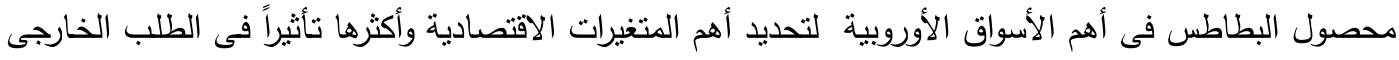

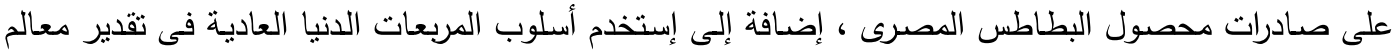
هذه الدالات ، وقد قدرت الدالات فى ثلاثة نماذج رياضية هى النموذج الخطى والنموذج الأسى (اللوغاريتمى)

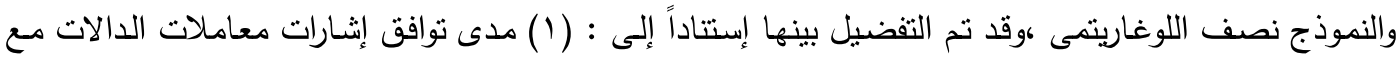

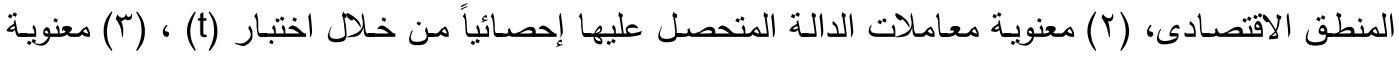
تأثثر المتغيرات المستقلة مجتمعة على المتغير التابع من خلال اختبار (F) ـ كما استخدم اختبار ديربن واتسون للكثف عن مدى وجود الارنباط الذاتى من عدمه. كما تم استخدام نموذج التعديل الجزئي لنيرولوف (D.W) فئلت Nerlove's partial Adjustment Model في أهم الأسواق الأوروبية. كما تم إستخدام نماذج التتبؤ بكمية الصادرات المصرية من محصول البطاطس لأهم

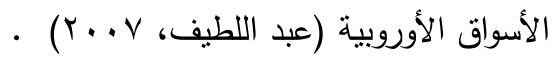

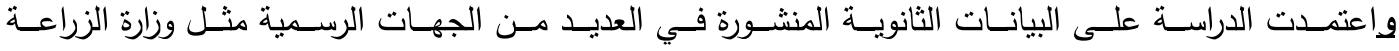

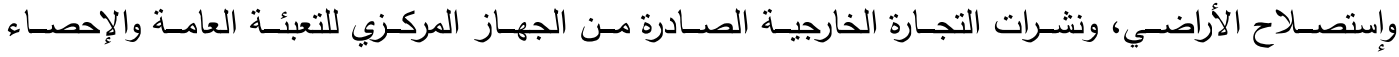
،بالإضـافة إلىى قاعدة بيانـات الجهـاز المركزى للتعبئسة العامسة والإحصساء على الموقـع الإلكترونسى، وقاعدة

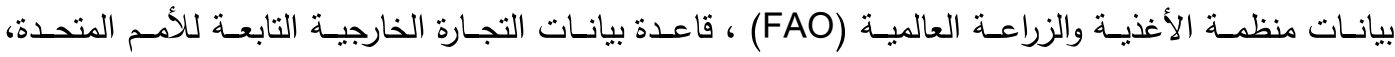

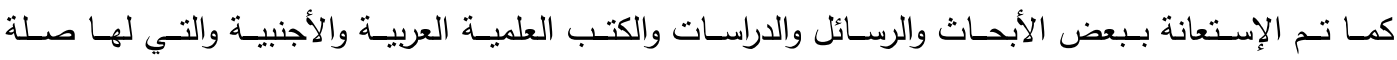




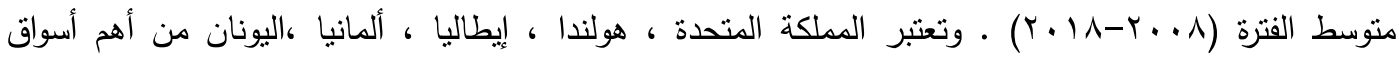

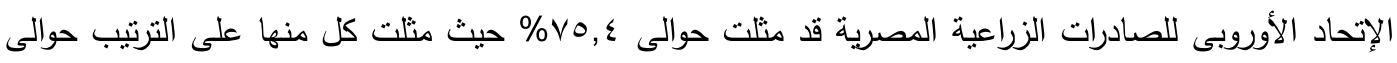

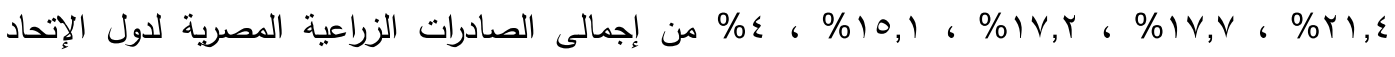

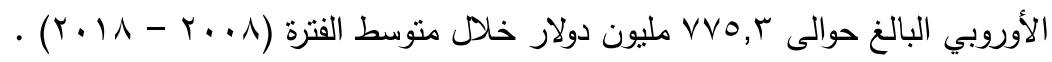

مشكثة البحث

تعتبر الصادرات من أهم المصادر الرئيسية لتوفير النقد الأجنبى خاصة في ظل وجود عجز في الميزان التجاري

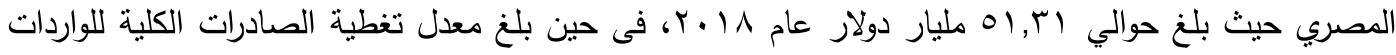

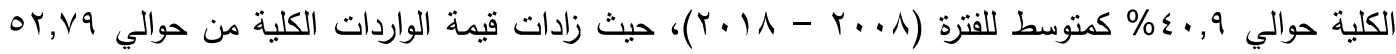

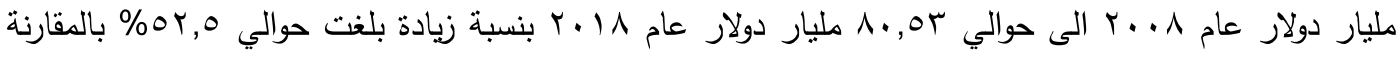

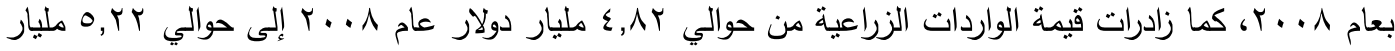

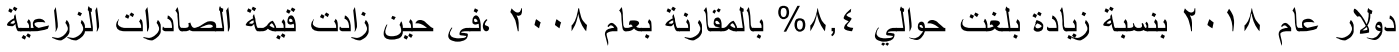

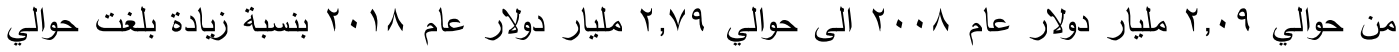

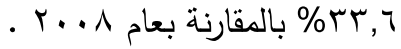
ويعتبر محصول البطاطس من أهم المحاصيل الزراعية التصديرية المصرية حيث بلغت قيمة صادرات محصول

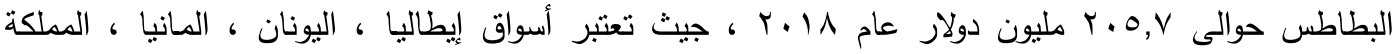

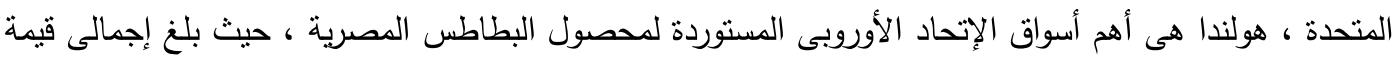

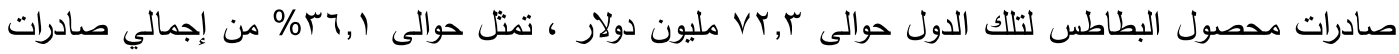

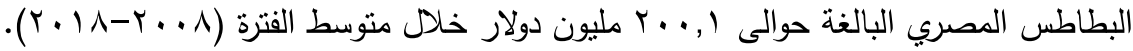
الإ أنه على الرغم من القدرة التتافسية التي تتمتع بها مصر في إنتاج وتصدير البطاطس ، الا أن كمية الصادرات

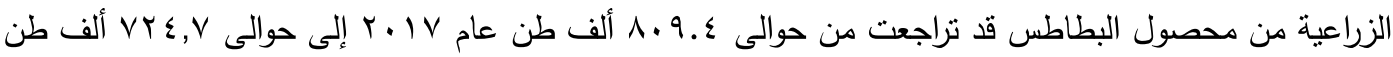

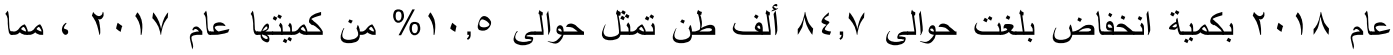
يستدعى معه دراسة القدرة التتافسية لمحصول البطاطس المصري في أهم أسواق الاتحاد الأوروبي للتوصل إلى هنى أسباب ذلك الانخفاض.

أهداف البحث يستهدف البحـث دراسـة تنافسية صـادرات البطـاطس المصـرى فـى أهـم أسـواق الإتحساد الأوروبـى مـن خـلد دراسة:

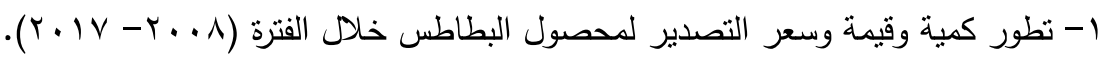

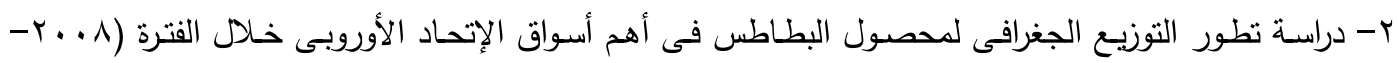
$\cdot(r \cdot) \mathrm{V}$ r- قياس القدرة التتافسية لصادرات محصول البطاطس فى أهم أسواق الإتحاد الأوروبى من خلال حساب مؤشرات

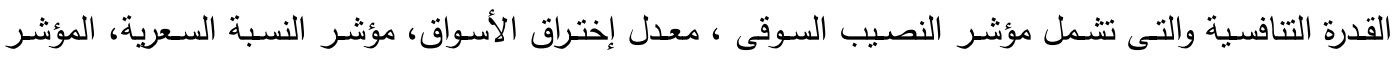
المركب للتنافسية. 


\title{
تنافسية صادرات البطاطس المصرية لأهم أسواق الاتحاد الأوروبي
}

\author{
حسام الدين محمد صديق \\ أستاذ الاقتصاد الزراعي المساعد - المعهد العالي للتعاون الزراعي \\ Hosseddik2000@yahoo.com
}

الملخص: يتتاول البحث دراسة القدرة التتافسية لصادرات البطاطس المصرية لأهم أسواق الإتحاد الأوروبى من

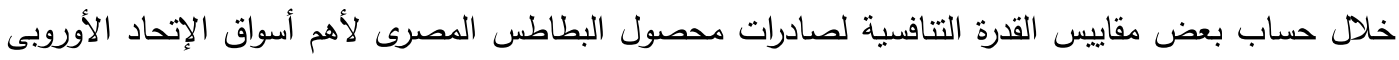

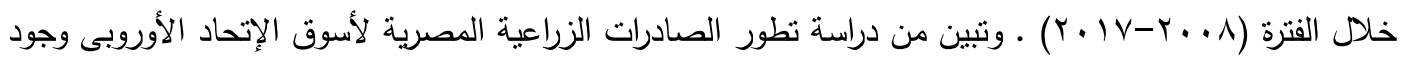

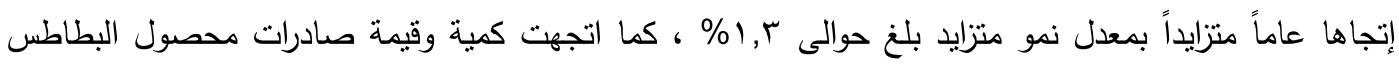

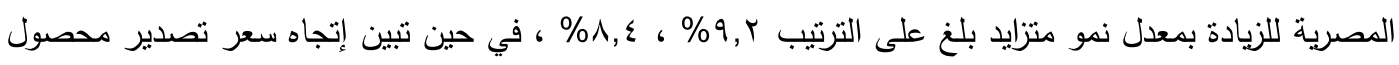

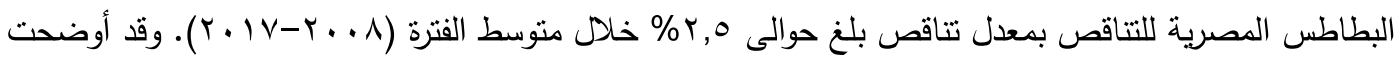

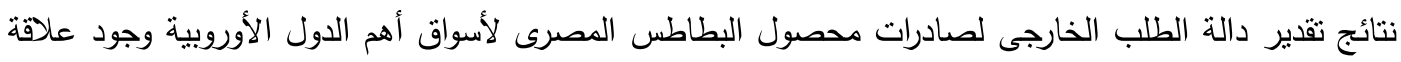

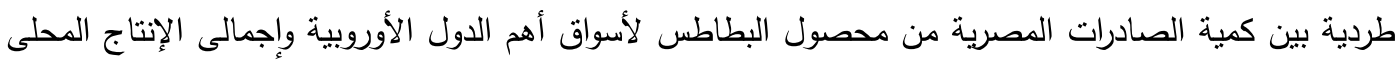

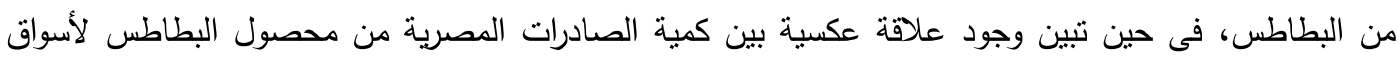
أهم الدول الأوروبية وكل من إجمالى الإستهلاك المحلى من البطاطس، ومتوسط سعر تصدير البطاطس. كما وقد أوضحت نتائج التقدير القياسي للمستوى المرغوب والمستهدف لصادرات البطاطس المصري لأهم الأسواق الأوروبية باستخدام نموذج التعديل الجزئي لنيرولوف Nerlove's partial Adjustment Mode/ أن أهم العوامل المحددة لصادرات البطاطس المصري لأهم الأسواق الأوروبية في المدى القصير والطويل تمثلت في الإنتاج المحلى من

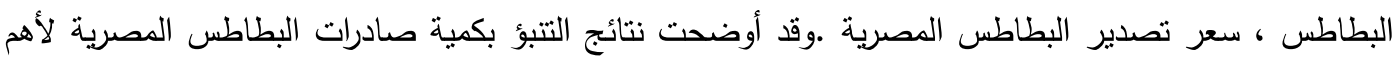

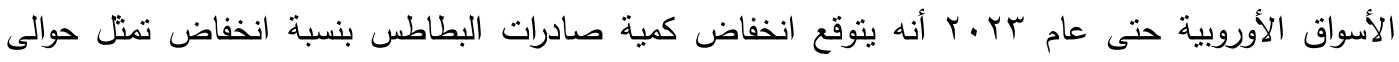

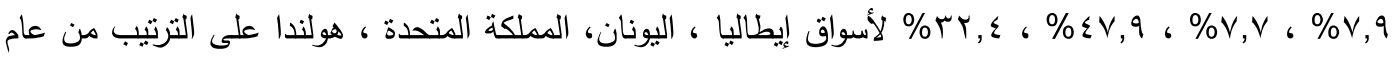

الكلمات المفتاحية: مؤشرات القدرة التتافسية - صادرات البطاطس المصرية - أسواق الإتحاد الأوروبي

مقدمة

يعتبر انخفاض مصادر النقد الأجنبى من أهم المشاكل التى تواجه الاقتصاد المصرى خاصة خلال الفترة الراهنة

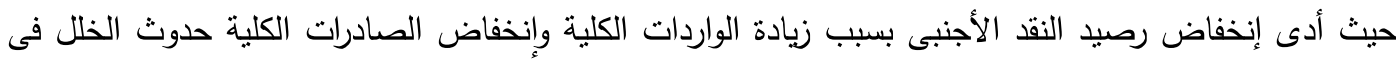
الميزان التجارى أدي إلى إعاقة تحقيق أهداف التتمية ، وبالتالى لابد من إتجاه السياسة العامة للدولة إلى تصحيح

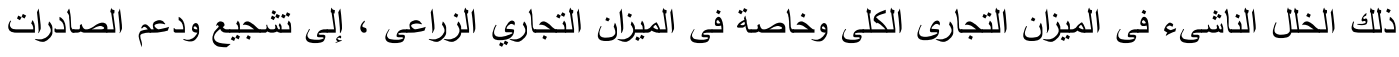

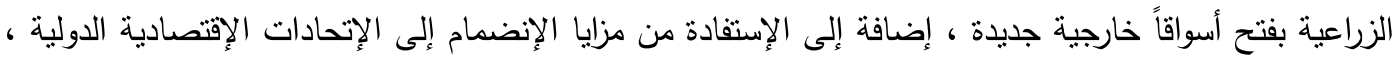

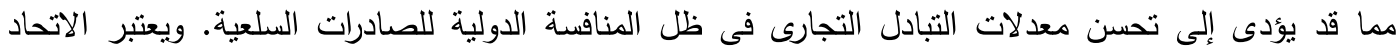
الأوروبي من أهم الإتحادات العالمية للتبادل التجارى والزراعى مع مصر حيث مثلت الصادرات الزراعية لدول

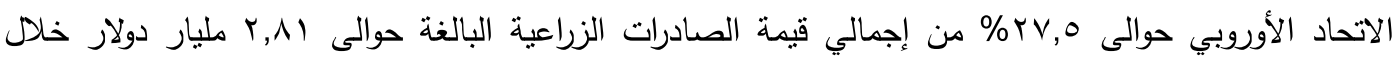

